\title{
Approaches to estimation of run-out distances for liquefied tailings
}

\author{
K.D. Seddon ATC Williams, Australia
}

\begin{abstract}
Estimates of runout distance of liquefied tailings from a failed dam may use strength-based approaches using either rheological parameters, or the critical state concept of undrained steady state strength. Problems associated with selection of rheological parameters are discussed. It is proposed that a reasonable approach is the assumption $\tau_{y}=s_{u s}$ and $\eta_{p}=0$. Energy/work based methods are used as a check on this assumption and found to give good agreement. The effect of assumptions regarding the volume of material incorporated in the slide area is also investigated using the energy-based equations. The results indicate that there is a limiting volume, above which significant increases in the runout distance do not occur.
\end{abstract}

\section{Introduction}

The estimation of expected runout distance from a failed tailings dam is a common design problem. In the case of most above-ground storages, runout distances will need to be addressed for the purpose of hazard/consequence assessment, even if the actual risk of failure is low.

In some cases an acceptable simplifying assumption may be to assume that the tailings will behave like water. However, this is likely to be very conservative, both with respect to the volume of material that will be involved in the flow, and with respect to the runout distance and time. Therefore, where an assessment based on the "behaves like water" assumption indicates unacceptable consequences, it is necessary to proceed to a more realistic analysis.

There are numbers of dam break and flood routing programs that are able to model the flow from a breached dam. Almost invariably these have been written in the first instance for the case of water dams. Some are very specialised and require considerable input effort. Some models do have an option to incorporate rheological parameters for the flowing liquid, but this only highlights the problem of what parameters to select. This is the subject of this paper.

A review of case histories of tailings dam failures does, however, show that it is not uncommon for a dam to fail at a time when (or possibly because) it is storing a considerable volume of free water. In this case all of the water flows out of the dam, and some of the tailings. The tailings release occurs as a typical flow slide of the order of hundreds to maybe a few thousand metres. On the other hand, the water entrains some tailings, which are carried as suspended solids. The released water flows for many kilometres downstream, to wherever the topography leads it, and the suspended tailings eventually settle out. This is subsequently reported as a tailings flow. This mechanism is not covered in this paper.

It is possible that risk assessments of tailings storages should address the question of both the consequences arising from of tailings release, and as well as the consequences of release of stored water, as a matter of routine.

\section{Strength of liquefied materials}

\subsection{Overview}

There are two basic approaches to quantifying the strength of material that has liquefied and been incorporated into a flow slide. The first is by use of rheological parameters. The second uses the critical state soil concept of undrained steady state strength. 
In some ways these are approaches from opposite sides of the problem. Rheology as a science deals with the flow of liquids. Flow slides may be considered as viscous fluids, and therefore amenable to analysis in this way. This type of approach is not uncommon for the analysis of mudflows (e.g. Coussot, 1996).

On the other hand, critical state theory starts from the concept of a loose, saturated soil, and addresses the question of what strength it will be reduced to as a consequence of shearing.

\subsection{Rheological approach}

The rheological approach typically characterises the soil as a viscoplastic material, using the Bingham model. In this model, the material is rigid up an initial yield stress, and thereafter flows as a viscous fluid, in which the induced shear resistance is a function of the shear rate. The general Bingham equation is:

$$
\tau=\tau_{y}+\eta_{p} \dot{\gamma}
$$

where:

$$
\begin{array}{ll}
\tau= & \text { shear stress }(\mathrm{kPa}) . \\
\tau_{y}= & \text { initial yield stress }(\mathrm{kPa}) . \\
\eta_{p}= & \text { plastic viscosity }(\mathrm{kPa} . \mathrm{sec}) . \\
\dot{\gamma}= & \text { shear strain rate }\left(\mathrm{sec}^{-1}\right) .
\end{array}
$$

Jeyapalan et al. (1983a, 1983b) present one well known method for the analysis of tailings dam failures, based on the use of these parameters. This method provides for the analysis of tailings flowing from a breached dam across a planar surface (i.e. it is a 2D analysis, applicable to a wide breach, and a generally flat downstream topography, that does not result in channelised flow). The published papers only present solutions for flow across a horizontal surface, but results for flow across sloping surfaces are available from Jeyapalan (1980). There is also a web site that provides a (non-guaranteed) calculator that will give solutions for a sloping plane.

\subsection{Critical state approach}

Critical state soil mechanics theory holds that for a given initial soil state (density and stress), a soil that is loaded in an undrained manner will deform until a constant strength condition is achieved, after which it will continue to deform, but will not accept any further changes in load. This is the steady state undrained strength $\left(\mathrm{s}_{\mathrm{uS}}\right)$. Soils that are susceptible to liquefaction exhibit stress responses that are a) contractive (showing a pore pressure increase when sheared) and b) brittle (after an initial peak, showing a reduction in strength when sheared). This response is typical of loose sands and silt/sand mixes. Many tailings materials fall within this category, and are therefore prima facie considered to be potentially liquefiable.

There are basically two approaches to estimation of the undrained steady state strength: laboratory testing, or correlation of in situ tests with back-calculated parameters. Olson and Stark (2002) provide a method for use of cone penetration test (CPT) data correlated against $s_{u s}$ results obtained by back-calculation from runout distances of previous liquefaction flow slides.

$$
s_{u s} / \sigma_{v o}^{\prime}=0.03+0.0143 q_{c 1} \pm 0.03
$$

Where:

$\sigma_{v o}^{\prime}=$ vertical effective stress, $\mathrm{kPa}$.

$q_{c 1}=$ normalised cone resistance, $\mathrm{MPa}$.

$$
q_{c 1}=q_{c} \frac{1.8}{0.8+\left(\sigma_{v o}^{\prime} / P_{a}\right)}
$$


$q_{c}=$ cone resistance, $\mathrm{MPa}$.

$P_{a}=$ reference pressure $(1 \mathrm{~atm}=100 \mathrm{kPa})$

Dillon and Wardlaw (2010) provide an example of CPT results and subsequent evaluation of undrained strength in tailings deposits using this method.

A method of analysis of runout distance which is amenable to use of undrained strength parameters is proposed by Hungr (1995), in the form of a dynamic analysis (program DAN). This program is able to accommodate a number of different formulations of strength relating to a variety of landslide types and geometries, one of them being the steady state undrained strength $\left(\mathrm{s}_{\mathrm{us}}\right)$. It is probable that programs of this type will eventually become industry standard. In the interim, they are not as well known, or as readily available, as some alternatives that use rheological parameters. Consequently it is considered that there is some value in improving the utility of rheological based programs, which is the subject of this paper.

\section{Influence of rheology on runout}

\subsection{Selection of parameters}

Typical rheology values that may apply to flow slides of liquefied material are suggested by Jeyapalan et al. (1983a) and are summarised in Table 1.

Table 1 Flow slide parameters of liquefied tailings

\begin{tabular}{lcc}
\hline & $\begin{array}{c}\text { Yield Stress } \\
\tau_{y} \text { (kPa) }\end{array}$ & $\begin{array}{c}\text { Plastic Viscosity } \\
\eta_{p} \text { (kPa.sec) }\end{array}$ \\
\hline Min & 1 & 0.1 \\
Max & 7 & 5 \\
\hline
\end{tabular}

These minimum and maximum bounds are illustrated in Figure 1, from which it is apparent that they encompass a relatively wide range.

The key problem of the rheological approach is therefore the selection of appropriate parameters for use in the analysis. In most cases the shear strengths will be well above the range that can be tested by conventional laboratory based techniques. The possible exceptions to this may be very high plasticity tailings that remain largely under-consolidated for significant periods of time, but these are not typical.

One possibility would be use of the 'shear vane in a bucket method' (e.g. Sofra and Boger, 2007). However (from a rheological perspective) the materials in question have to be considered as very dense slurries, and a fundamental question is whether any testing of this type can be assured of being undrained. There are two possibilities. One is that drainage will occur from the zone of soil being sheared, resulting in an overestimate of strength. The other is that the sheared zone will dilate during initial shearing, and additional water will migrate into the zone, resulting in an under-estimate of shear strength. Both of these are undesirable, and it is recommended that test results of this nature should not be relied upon.

The alternative approach would be back analysis of documented slides, and correlation against some in situ parameter, in the same way that CPT results have been correlated with $\mathrm{s}_{\mathrm{us}}$. So far this type of correlation is not available, probably not least because it would require derivation of two parameters instead of one.

However if this type of approach was carried out, one of the bounds would be to set $\eta_{p}=0$. This would give a value of $\tau_{y}$ that was effective equal to a value of $\mathrm{S}_{\mathrm{us}}$ derived from a critical state perspective. 


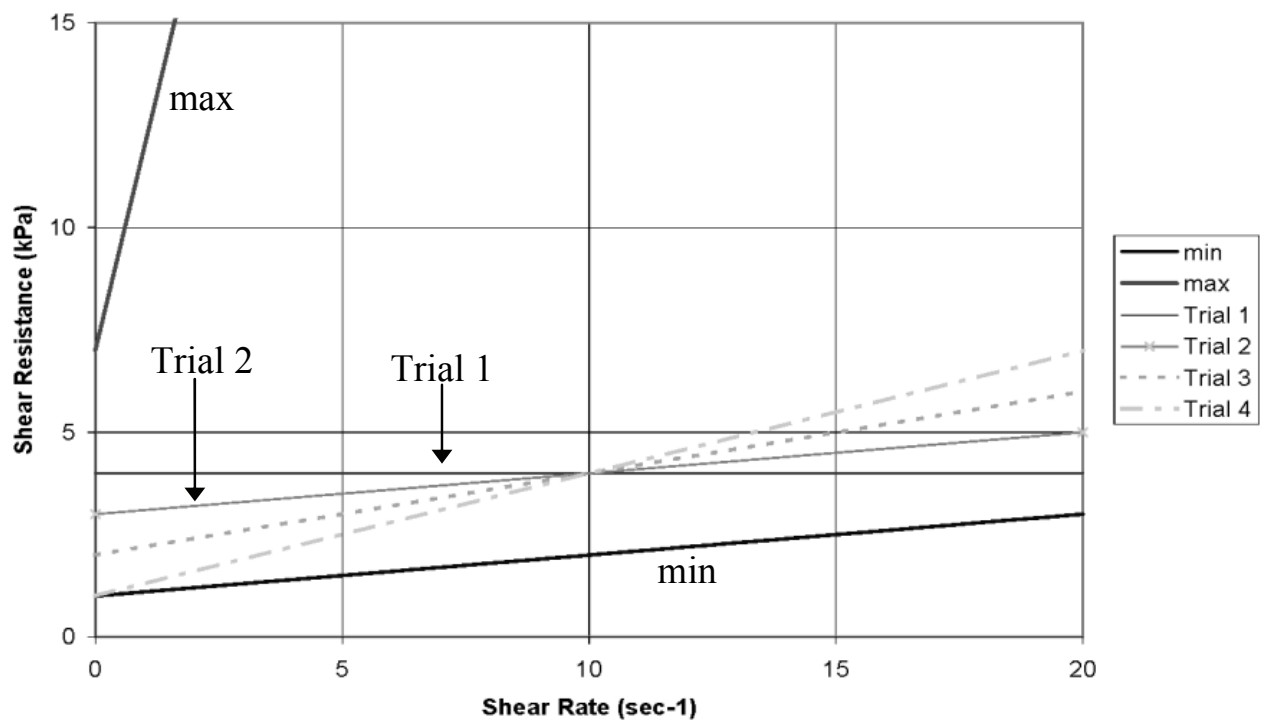

Figure 1 Trial rheology parameters

Consequently it is postulated that predictions using rheological models can be based on the following parameters:

$$
\begin{aligned}
& \eta_{p}=0 \\
& \tau_{y}=s_{u s}
\end{aligned}
$$

This has obvious advantages when it comes to parameter selection. The following sections investigate the likely effect of this assumption.

\subsection{Influence of shear rate and viscosity}

To investigate the likely effect of the $\eta_{\mathrm{p}}=0$ assumption, it is first appropriate to consider the likely magnitude of the shear strain rate $(\dot{\gamma})$. An estimate for this can be obtained from the following (Jeyapalan et al., 1983a):

$$
\dot{\gamma}=2 v / h
$$

Where:

$$
\begin{aligned}
& v=\quad \text { flow velocity. } \\
& h=\quad \text { flow depth. }
\end{aligned}
$$

If we take (say) $v=10 \mathrm{~m} / \mathrm{sec}, h=2 \mathrm{~m}$, the resulting value for $\dot{\gamma}$ is only $10 \mathrm{sec}^{-1}$. This is not particularly high, and consequently any adopted value for $\eta_{p}$ greater than zero would need to be large to have a great influence.

A trial calculation was carried out using the Jeyapalan method with a range of input parameters. In all cases an initial embankment height of $10 \mathrm{~m}$, and a horizontal runout base were used. Yield stress and viscosity were varied as shown in Table 2, and illustrated in Figure 1. The reason for the choice of this combination of parameters was to obtain equal values of shear resistance at a shear strain rate of $10 \mathrm{sec}^{-1}$.

The results are summarised in Table 2, and indicate that whilst there is significant variation in runout time (and hence velocity), the actual variation in runout distance is not great. 
Table 2 Results of varying input rheology

\begin{tabular}{llcccc}
\hline & & \multicolumn{5}{c}{ Example } \\
& & 1a & $\mathbf{1 b}$ & $\mathbf{1 c}$ & $\mathbf{1 d}$ \\
\hline Height $(\mathrm{H})$ & $\mathrm{m}$ & 10 & 10 & 10 & 10 \\
Density & $\mathrm{kN} / \mathrm{m}^{3}$ & 18 & 18 & 18 & 18 \\
$\mathrm{~S}_{\mathrm{us}}\left(=\tau_{\mathrm{y})}\right.$ & $\mathrm{kPa}$ & 4 & 3 & 2 & 1 \\
Bingham viscosity $\left(\eta_{\mathrm{p}}\right)$ & $\mathrm{kPa} \cdot \mathrm{sec}$ & 0 & 0.1 & 0.2 & 0.3 \\
Runout distance & $\mathrm{m}$ & 165 & 165 & 170 & 185 \\
Runout time & $\mathrm{sec}$ & 19 & 26 & 28 & 34 \\
\hline
\end{tabular}

\section{$4 \quad$ Energy based approximations}

\subsection{Introduction}

This section presents two simple energy based methods that can be used either as stand-alone calculations, or as a cross check on more detailed analyses. The approach is based on equating loss of potential energy in the sliding mass with the work generated in opposition to the slide (Hungr, 1995). Both of these methods are presented for the case of flow over a horizontal plane. However the analysis can easily be extended to a sloping runout surface if required.

The geometry of the slide is defined in Figure 2, which shows the pre-slide and post-slide configurations. It is necessary to make an initial estimate of the volume of material that will be involved in the slide. This is then idealised as a rectangular mass, with the actual embankment configuration being ignored. Resistance from any material that does not liquefy is also ignored.

A single representative value of the post-liquefaction shear strength $\left(\mathrm{s}_{\mathrm{us}}\right)$ must be selected.

\subsection{Linear method}

The simplest solution can be obtained if it is assumed that the runout tongue is of uniform thickness.

From the geometry,

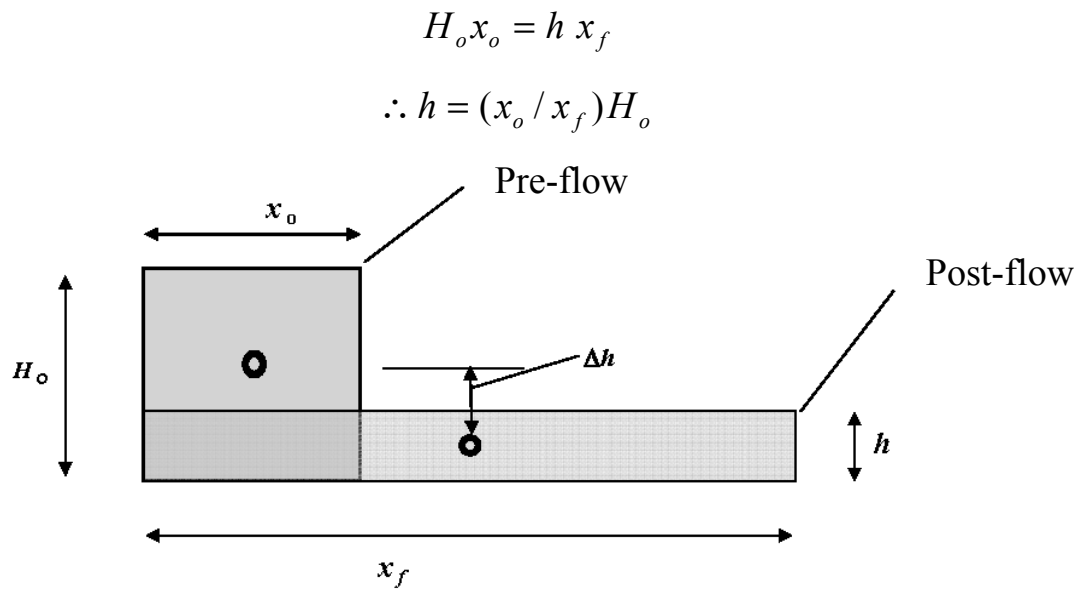

Figure 2 Simplified flow slide geometry

The change in potential energy is:

$$
\Delta P E=M \Delta h=\not x_{o} H_{o}\left(H_{o}-h\right) / 2
$$


The work resisting sliding is:

$$
\Delta W=\bar{F} \Delta x=s_{u} \frac{\left(x_{o}+x_{f}\right)}{2} \frac{\left(x_{f}-x_{o}\right)}{2}=s_{u}\left(x_{o}+x_{f}\right)\left(x_{f}-x_{o}\right) / 4
$$

Equating potential energy and work:

$$
\triangle P E=\Delta W
$$

Hence,

$$
\gamma x_{o} H_{o}\left(H_{o}-h\right) / 2=s_{u}\left(x_{o}+x_{f}\right)\left(x_{f}-x_{o}\right) / 4
$$

and re-arranging gives:

$$
x_{f}^{2}+x_{o} x_{f}-2 x_{o} H_{o}^{2} / s_{u}=0
$$

in which $x_{f}$ is the only unknown, and the required runout distance (Ro) is:

$$
R o=x_{f}-x_{o}
$$

\subsection{Hungr method}

The original approach presented by Hungr (1995) is only marginally more complex. He assumes the runout tongue is parabolic in shape. The resulting closed form solution is a cubic equation:

$$
x_{f}^{3}-\left(x_{o}^{2}+2 \gamma H_{o}^{2} x_{o} / s_{u}\right) x_{f}+9 \gamma H_{o}^{2} x_{o}^{2} / 4 s_{u}=0
$$

Again, the run-out distance is obtained from (7).

\section{Comparison of results}

\subsection{Calculation of runout distance}

A series of additional comparisons was undertaken to assess the influence of variability of geometry and strength parameters on the model results. The input data are summarised in Table 3. A range of embankment heights was investigated. The equivalent width of failed material was taken as $10 \mathrm{x}$ height in all cases. This implies a post failure slope of the order of 5\% in the material left in- situ in the storage after the failure. In all cases a bulk density of $18 \mathrm{kN} / \mathrm{m}^{3}$ was assumed. In cases 1 and 2, the strength $s_{\text {us }}$ was taken to be equal to $0.05 \sigma_{v}^{\prime}$. Case 3 is based on an example quoted by Hungr (1995) and uses a lower value of strength. The apparent precision in the numerical value is the result of a hard conversion from the original imperial units. Example $3 \mathrm{~B}$ is included as a further examination or the effect of introducing a non-zero value for plastic viscosity.

Table 3 Summary of example input data

\begin{tabular}{llcccc}
\hline & & \multicolumn{4}{c}{ Example } \\
& & $\mathbf{1}$ & $\mathbf{2}$ & $\mathbf{3 A}$ & $\mathbf{3 B}$ \\
\hline Height $(\mathrm{H})$ & $\mathrm{m}$ & 10 & 10 & 30.5 & 30.5 \\
Failed width $\left(\mathrm{x}_{\mathrm{o}}\right)$ & $\mathrm{m}$ & 100 & 200 & 305 & 305 \\
Density & $\mathrm{kN} / \mathrm{m}^{3}$ & 18 & 18 & 18 & 18 \\
$\mathrm{~S}_{\mathrm{u}\left(=\tau_{\mathrm{y}}\right)}$ & $\mathrm{kPa}$ & 4 & 8 & $2.39 *$ & $2.39^{*}$ \\
Bingham viscosity $\left(\eta_{\mathrm{p}}\right)$ & $\mathrm{kPa} \cdot \mathrm{sec}$ & $\mathrm{NA}$ & $\mathrm{NA}$ & $\mathrm{NA}$ & 0.02 \\
\hline
\end{tabular}

*Note: $2.39 \mathrm{kPa}=50 \mathrm{psf}$ in imperial units. 
Runout distances were calculated using the Jeyapalan method, and both of the approximate energy based methods. The results of the computed runout distances are presented in Table 4.

A comparison of the results for cases 1 and 2 indicates that all the models appear to be internally consistent, in that doubling the height and strength results in a doubling of the runout distance. In all cases the Jeyapalan model predicts longer runout distances.

The results for case 3A include a value for the DAN model, given by Hungr (1995). It is notable that both the energy based Equations (6) and (7) are in both in good agreement with the DAN model, and with each other. The calculation for example $3 \mathrm{~B}$ includes a non-zero value $\eta_{\mathrm{p}}$ and is only applicable to the Jeyapalan procedure. The result again indicates that the effect of plastic viscosity is somewhat limited compared to shear strength.

\section{Table 4 Summary of results of runout calculations}

\begin{tabular}{|c|c|c|c|c|}
\hline \multirow[b]{3}{*}{ Model } & \multicolumn{4}{|c|}{ Example } \\
\hline & 1 & 2 & $\mathbf{3 A}$ & 3B \\
\hline & \multicolumn{4}{|c|}{ Runout Distance (m) } \\
\hline Jeyapalan & 165 & 330 & 2,560 & 2,400 \\
\hline Linear approximation - Equations (6) and (7) & 154 & 308 & 1,615 & \\
\hline Hungr - Equations (7) and (8) & 141 & 281 & 1,591 & \\
\hline DAN & - & - & 1,545 & \\
\hline
\end{tabular}

\subsection{Influence of sliding volume}

The energy based Equations (6) and (8) were further used to investigate the influence of the volume of liquefied material on the runout distance. The input data was the same as in Example 2 (Table 3), except that the volume was varied. The volume of failed material is an explicit input into Equations (6) and (7) in the form of the initial width $x_{o}$.

The results of the calculations are summarised in Table 5. The results are of interest in that they indicate that the runout distance is not sensitive to slide volume, and in fact it reaches a limiting value. Increases in assumed volume above this value do not result in any increase in calculated runout distance.

The Jeyapalan method does not use volume as an input and hence the result cannot be varied as a function of volume. However, the results can be used to calculate the volume of the run-out tongue. For the case of Example 2, the runout volume has been calculated to be equivalent to a failed width of around $70 \mathrm{~m}$. As some of the slumped material remains behind the original embankment location, this is clearly an underestimation of the total failed volume. This suggests that the implied volumes in the Jeyapalan method are of the same order as those assumed in the energy based methods in this example.

Table 5 Calculated runout for varied sliding volume

\begin{tabular}{lcccc}
\hline Failed width (m) & $\mathbf{7 0}$ & $\mathbf{1 5 0}$ & $\mathbf{2 0 0}$ & $\mathbf{2 5 0}$ \\
& \multicolumn{5}{c}{ Runout Distance (m) } \\
\hline Jeyapalan & 330 & & & \\
Linear - Equations (6) and (7) & 252 & 300 & 308 & 307 \\
Hungr - Equations (7) and (8) & 250 & 280 & 281 & 268 \\
\hline
\end{tabular}




\section{Conclusions}

It is concluded that reasonable estimates of runout distance may be obtained by use of the $\eta_{p}=0$ assumption in rheological based methods, with $\tau_{y}=s_{u s}$.

The simple energy based methods can be used as a check, or as a quick method of providing initial estimates.

The calculations indicate that there is a limiting runout distance which (for a given dam configuration) does not increase with increases in the volume of liquefied material.

\section{References}

Coussot, P. (1996) Mudflow Rheology and Dynamics, Taylor and Francis.

Dillon, M.J. and Wardlaw, H.J. (2010) Strength and Liquefaction Assessment of Tailings, in Proceedings First International Seminar on the Reduction of Risk in the Management of Tailings and Mine Waste (Mine Waste 2010), A.B. Fourie and R.J. Jewell (eds), 29 September - 1 October 2010, Perth, Australia, Australian Centre for Geomechanics, Perth, Australia, pp. 347-360.

Hungr, O. (1995) A model for the runout analysis of rapid flow slides, debris flows, and avalanches, Canadian Geotechnical Journal, Vol. 32, pp. 610-623.

Jeyapalan, J.K. (1980) Analyses of Flow failures of Mine Tailings Impoundments, PhD Thesis University of California, Berkeley, Calif.

Jeyapalan, J.K., Duncan, J.M. and Seed, H.B. (1983a) Analyses of flow failures of mine tailings dams, ASCE Journal of Geotechnical Engineering, Vol. 109, No. 2, pp. 150-171.

Jeyapalan, J.K., Duncan, J.M. and Seed, H.B. (1983b) Investigation of flow failures of tailings dams, ASCE Journal of Geotechnical Engineering, Vol. 109, No. 2, pp. 172-189.

Olson, S. and Stark, T. (2002) Liquefied Strength Ratio from Liquefaction Flow Failure Case Histories, Canadian Geotechnical Journal, Vol. 39, pp. 627-647.

Sofra, F. and Boger, D.V. (2007) The bucket rheometer for thickened tailings and paste flow curve determination, in Proceedings Tenth International Seminar on Paste and Thickened Tailings (Paste07), A.B. Fourie and R.J. Jewell (eds), 13-15 March 2007, Perth, Australian Centre for Geomechanics, Perth, Australia, pp. 249-257. 